\title{
La educación en los escritos de Eduardo Mallea y su método Kierkergaardiano"
}

\author{
The education in the letters of Eduardo Mallea and his kierkergaardian \\ method
}

\section{A educação nas letras do Eduardo Mallea e seu método kierkergaardiano

\author{
Martín Omar Aveiro² \\ Universidad Nacional del Sur, Profesor. \\ https://orcid.org/0000-0001-6695-2301
}

Resumen: El presente artículo es parte del proyecto de investigación: “Aspectos académicos y pedagógicos en los entramados discursivos de Eduardo Mallea", radicado en el Departamento de Humanidades de la Universidad Nacional del Sur, entre los años 2017 y 2018. El mismo da cuenta de como aquellas cuestiones que hacen a la problemática educativa aparecen en la obra literaria del autor argentino, nacido en la ciudad de Bahía Blanca, situada en la costa atlántica dentro de la provincia de Buenos Aires. En esta ocasión ponemos en sintonía su pensamiento con los aportes derivados de los escritos filosóficos del dinamarqués Sören Kierkegaard, en tanto pensador de la diferencia y, por ende, un agudo crítico de las concepciones que arrastra la modernidad. Temáticas que componen significativamente las letras del bonaerense y nos permiten un giro lingüistico para la filosofía de la educación.

Palabras clave: Eduardo Mallea. Educación. Letras. Lenguaje. Kierkegaard.

Abstract: The present article is part of the research project: "Academic and pedagogical aspects in the discursive frameworks of Eduardo Mallea", located in the Department of Humanities of the Universidad Nacional del Sur, between 2017 and 2018. The same one gives account of how those questions that do to the educational problematic appear in the literary work of the Argentine author, born in the city of Bahía Blanca, located on the Atlantic coast within the province of Buenos Aires. On this occasion we put his thoughts in sync with the contributions derived from the philosophical writings of the Danish Sören Kierkegaard, as a thinker of difference and, thus, an acute critic of the conceptions that modernity drags. Thems that make up the lyrics of the bonaerense and allow us a linguistic turn for the philosophy of education.

Keywords: Eduardo Mallea. Education. Literature. Language. Kierkegaard.

Este texto es parte del Proyecto Investigación 2017-2018, radicado en el Departamento de Humanidades de la Universidad Nacional del Sur, denominado: “Aspectos académicos y pedagógicos en los entramados discursivos de Eduardo Mallea".

2 Doctor en Humanidades y Artes con mención en Ciencias de la Educación por la Universidad Nacional de Rosario; Licenciado en Ciencias de la Educación por la Universidad Nacional de Cuyo. 
Resumo: 0 presente artigo é parte do projeto de pesquisa: "Aspectos acadêmicos e pedagógicos nos emadeiramentos discursivos de Eduardo Mallea", localizado no Departamento de Humanidades da Universidad Nacional del Sur. 0 mesmo da conta de como as questões que fazem o problema educacional aparecem na obra literária do autor argentino, nascido na cidade de Bahía Blanca, localizada na costa atlântica da província de Buenos Aires. Nesta ocasião, colocamos seus pensamentos em sintonia com as contribuições derivadas dos escritos filosóficos do dinamarquês Sören Kierkegaard, como um pensador da diferença e, portanto, um crítico agudo dos conceitos que a modernidade arrasta. Assuntos que compõem significativamente as letras do bonaerense e nos permitem uma virada linguística para a filosofia da educação.

Palavras chave: Eduardo Mallea. Educação. Literatura. Linguagem. Kierkegaard.

Recebido em 11 de outubro de 2019

Aceito em 11 de março de 2020

Publicado em 23 de julho de 2020

\section{INTRODUCCIÓN}

[...] lo que aquellos hombres tenían de malo era un mal simple, era el modo sin vida como vivian, aprendian y enseñaban. (Mallea, 1937).

La filósofa y lingüista búlgara, Julia Kristeva (1988), afirma que la literatura es el terreno privilegiado en que se ejerce el lenguaje. Además, como asegura Bourdieu (2002, p. 45), es en la literatura donde podemos descubrir los sentimientos profundos de una generación y las manifestaciones del inconsciente cultural de una época: "Por ello, incluso, la relación que el intelectual sostiene necesariamente con la escuela y con su pasado escolar tiene un peso determinante en el sistema de sus elecciones intelectuales más inconscientes." De ahí que, nos interesa bucear en las letras del escritor argentino Eduardo Mallea (Bahía Blanca, 1903 Buenos Aires, 1982), pues de sus textos se desprenden aspectos académicos y pedagógicos para la reflexión educativa a partir del método de escritura utilizado por el filósofo danés Sören Kierkegaard (Copenhague, 1813 - 1855), de comunicación indirecta: "[...] un modo de comunicar que siempre está pendiente de que cada lector desencadene un sentido que sólo a él le atañe." (CUERVO, 2010, p. 20). ${ }^{3}$ En ese sentido, se ponen en valor la utilización de las fuentes literarias para la investigación filosófica (DOMÍNGUEZ et al., 2011), en este caso, de la educación. 
Mallea desde sus primeros ensayos, como Historia de una pasión argentina de 1937, nos brinda detalles autobiográficos e imaginarios de su paso por la escuela. Esto, permite contrastar su trayectoria en un Instituto británico privado, en el Colegio Nacional de Bahía Blanca y, más tarde, como estudiante de bachillerato o de la Facultad de Derecho de la Universidad de Buenos Aires. Asimismo, se referencia en los ascendientes de su padre sanjuanino Narciso Segundo Mallea (1858-1941), pariente de Domingo F. Sarmiento, mencionados en la autobiografía Recuerdos de Provincia (1850), ${ }^{4}$ y del que se diferencia, sobre todo por el antagonismo que aquel había expuesto entre la civilización y la barbarie. Mallea invierte estos términos, para pensar en la apariencia visible - del mero representar - y la invisible interior - de un país que es preciso hacer nacer. Para el escritor del sudoeste bonaerense, aquel aparentar en los ámbitos educativos se hacían visible en la indolencia de los profesores argentinos, "bostezantes" profesionales, monótonos y rutinarios, que le enseñaban con desgano las disciplinas escolares: "Si antes había aprendido en inglés quien era San Martín, aquí comencé a olvidarlo tenazmente." (MALLEA, 2001, p. 18).

Cuestiones que sirven, a modo de ejemplo, para focalizar en nuestro objeto de estudio sobre el recorrido de sus obras literarias que pretendemos problematizar desde una perspectiva kierkergaardiana. Pues, Kierkegaard es el pensador contemporáneo que despliega el problema de la escritura y de la lectura, ningún autor antes que él puso en cuestión esa praxis como una posición de la existencia y de interpelación pedagógica a la comunidad (CUERV0, 2010), presentes en las letras malleanas. Así es, su discurso literario se compone de elementos experienciales e imaginarios, vivenciales y ficcionales, para brindarnos, en su estética de lenguajes, la posibilidad de desentramar hilos de comprensión en la madeja de relaciones que establece Mallea entre sus novelas o ensayos y su propia trayectoria educativa, vivenciada entre Bahía Blanca y Capital Federal. Son esas ciudades las que inspiran la composición de su escritura y le permiten pensar el país desde un ángulo singular. Allí, sitúa paisajes, imágenes, y reflexiones de su transcurrir por la educación y su crítica, en ocasiones radical, hacia los ámbitos académicos de enseñanza.

después de Temor y temblor Kierkegaard declarará como su 'estrategia de comunicación indirecta', puesto que lo que hay para comunicar no es un saber que se pueda transmitir de modo directo, sino algo que sólo se puede comprender de un modo oblicuo, de modo que el lector tenga que tomar una decisión acerca de su sentido. Este juego de cajas chinas es un complejo mecanismo de escritura que está lejos de ser la mera exposición 'literaria' de un saber que podría transmitirse de manera más sencilla. Mediante este dispositivo, Kierkegaard señala un obstáculo decisivo para la comprensión del relato, la dificultad de ponerse en el lugar del otro." (CUERVO, 2010, p. 18).

4 Los Mallea, según Sarmiento (2000), descendían de una antigua familia de abolengo de la provincia de San Juan, que se remontan hasta su fundación en el siglo XVI, cuando don Juan Eugenio de Mallea, segundo de la expedición de Juan Jufré, llegó procedente de Perú en 1552 y contrajo nupcias con la hija de Juan Huarpe, cacique de Angaco, doña Teresa de Ascencio. 


\section{YO NO PUEDO ENSEÑAR, YO NO PUEDO - NI QUIERO - OBLIGAR NINGÚN PENSAMIENTO...}

Mallea, efectivamente, se rebela contra la profesión de enseñante. Se corre de cierta obsesión pedagogizante, en sus variantes pedantescas. Sentía cierta execración por los eruditos y pasión por los creadores, abominaba a los letrados y admiraba a quienes admitían amanecer sobre ignorancias, se horrorizaba frente a la intelectualización mecanizada de los que están sentados sobre el sitial de sus letras. Criticaba a los petulantes grises, hombres vacuos, que habían sido sus profesores en la Facultad de Derecho, por su falta de humanidad y de pasión, su modo sin vida como vivían y enseñaban, su privación de vida. Por eso se negaba a enseñar, a instruir, y pretendía tan sólo conmover (MALLEA, 2001). Ahora bien, ટ̇qué puede significar, en la discursividad malleana, conmoverę, żqué implicancias puede tener un efecto de conmoción frente a uno de instrucción o de enseñanza? żqué aspectos distintos movilizan en los sujetos ambas nociones que Mallea insiste en diferenciar?

La palabra conmover contiene una polisemia que es preciso aclarar. Pues, puede ser utilizada para algo que perturba, violenta, inquieta, altera, a individuos o a sociedades. También se aplica, en la clínica médica, para significar un trastorno en el cerebro que puede llevar a la pérdida de conocimiento y memoria en casos extremos. Aunque, por otra parte, es usada como sinónimo de emocionar, enternecer, mover a com-pasión. Es decir, a-pasionar $y$, tal vez, esta sea la acepción más precisa que Mallea le quiso dar a su término. La pasión significa, en su vocabulario, sufrimiento, padecimiento, dolor y pena que, a la vez, reclama y libera (EDUARDO MALEA...., 2015). Es la pasión la que moviliza, y no la reflexiva razón (KIERKEGAARD, 1995), la búsqueda de emociones establecidas en reminiscencias originarias. En clave platónica, la ciencia es reminiscencia que debemos buscar en los orígenes de los sentimientos, conductas y naturalezas. Husmear debajo de la superficie, en la experiencia subterránea del rizoma. En esto consistía la división clasificatoria que establece entre una Argentina visible y otra invisible, donde radican los auténticos valores del hombre argentino (RIVELU, 1969; PINTOR GENARO, 1976; POLT, 1959). Incluso, en el libro La bahía del silencio de 1940, le puso un nombre:

Juan Argentino, nuestro hombre -me decía-, es explotado por el que lo vende. Lo que importa es que busquemos en todas partes, obstinadamente, a Juan Argentino. Que lo distingamos de su expoliador, que le demos el lugar que ha merecido por su digna desventura. Juan Argentino es el ignorado, el desconocido; en cambio, Juan Inglés, Juan Italiano, Juan Alemán, todos esos juanes, son los amos. Juan Argentino es como un niño, es menester, entonces, que hagamos de él el hombre nuevo.

Juan Argentino -me decía- siente en la ciudad, sufre y espera en el campo, vive en todas partes de su tierra. A ese sentimiento, a ese dolor, a esa presencia hay que darles inteligencia, expresión. (MALLEA, 1940, p. 75-76). 
El país visible, como dijimos, era el del mero representar, aparentar, interpretar un papel en un escenario trivial y que, a su vez, servía de molde al recién llegado para conformarlo a su imagen y semejanza. Una apariencia de aristocracia y refinamiento que ocultaban una intrínseca barbarie. En cambio, en el hinterland, el interior profundo, tierra adentro, Mallea (2001) descubría a los argentinos invisibles. En el trabajo labriego, el médico rural, los hombres solitarios de ciencia, los enseñantes mal pagos y hambreados, periodistas que corrigen en silencio a eminentes que luego brillan por la prosa de sus artículos. En ese silencio creador, sacrificado, que se yergue por encima de toda utilidad, el escritor encuentra una nueva Argentina frente a la que rige en la esfera pública y académica, en sus ambiciosas ficciones exaltadas.

Es en esa invisibilidad creadora que el escritor se encuentra con su patria, con su tierra, frente a la magnífica Europa y la lógica de la Razón que todo lo abarca y todo lo encubre. Es preciso ubicar sus principales e incipientes obras en una época de entre guerras, desde 1918 fin de la Primera Guerra Mundial e inicios de la Segunda. Es un período en el que frente al panorama bélico internacional se abren diversas corrientes de interpretación sobre la cuestión nacional (AVEIRO, 2014; PINTOR GENARO, 1976). Sin embargo, Mallea (2001) no busca la nacionalidad en una elucubración intelectual. Es más, lo intelectual le repugnaba. Solamente podía concebir lo intelectual como camino para llegar a la sabiduría, para lo cual había que ir mucho más lejos que una somera erudición. La nacionalidad la descubría en la soledad creadora que llamaba destierro. Destierro de la civilización, del precedente europeo. Si bien elude las cuestiones económicas, su crítica política se centra en cuestiones morales y espirituales. Es en una mezcla de fuego pasional y heroísmo, frente a la fría lógica racional, en que encuentra el fundamento de lo argentino. De allí se desprende una consecuencia netamente pedagógica: enseñar equivale, en sus argumentos, a mostrar. No de-mostrar lógicamente, racionalmente, sino mostrar. Mostrar el rostro oculto, invisible, de la argentinidad. No persigue obligar ningún pensamiento sino, simplemente, mostrar a la Argentina profunda que lo reconciliaba consigo mismo y lo enfrentaba al pasado civilizatorio de su escolaridad y, también, de su ancestralidad sarmientina.

\section{UNA IDENTIDAD QUE SE BUSCA EN LA INTERIORIDAD}

En la primera mitad del siglo XX nos encontramos con escritores argentinos que repiensan su herencia finisecular. Algunos intelectuales intentan diferenciarse de los dogmas de interpretación positivista (BIAGINI, 2010) y se lanzan en la búsqueda de su propia identidad 
nacional, con diversos matices. Otros revalorizan la hispanidad, en contraste con la anglofilia y francofilia anterior, para encontrar elementos autóctonos de comprensión. De acuerdo a lo señalado por Romero (1987), entre 1912 y 1919 Alejandro Korn elabora su Influencias filosóficas en la evolución nacional; entre 1917 y 1922 se publica la Historia de la literatura argentina, de Ricardo Rojas; y José Ingenieros da a la imprenta, entre 1918 y 1920, La evolución de las ideas argentinas. Impulso de búsqueda identitaria que se prolongará en las décadas siguientes con perfiles literarios e ideológicos diversos en los escritos de Leopoldo Lugones, Manuel Gálvez, Ezequiel Martínez Estrada, Eduardo Mallea o de los filósofos Coriolano Alberini, Carlos Astrada y Luis Juan Guerrero (ALEMIAN, 2004).

Un nuevo eticismo, asentado en valores espirituales, se alzaba contra el positivismo, el cientificismo y el economicismo. Es alli donde encuentra anclaje discursivo la proclama malleana. También, en la fuerte influencia paterna, por quien sentía una profunda admiración. Un ilustrado médico cuyano, que había militado en las filas de la Unión Cívica junto a Guillermo Udaondo y llegó a ser, en dos ocasiones, jefe comunal de Azul en la provincia de Buenos Aires. ${ }^{5}$ Al respecto, sostiene Mallea (2001, p. 15) sobre su padre: "[...] su pobreza de hombre que pudo ser muy rico, en esa espartana sencillez y ese carácter, duro como una barra, que le llevaron a no aceptar nunca una situación dependiente." En consecuencia, abandonó, por completo, la actividad partidaria y se dedicó por entero a la educación de sus tres hijos, entre ellos de Eduardo. En sintonía, el enfoque moralista impregnaba la ensayística latinoamericana pedagógica, jurídica y literaria durante las primeras décadas del siglo XX. El énfasis puesto en lo espiritual que rige lo material se manifestaba en la actividad política y educativa sobre supuestos de igualdad y justicia.

De ahí que, en 1941, Eduardo Mallea recordaba satisfactoriamente la llegada a la presidencia de Hipólito Yrigoyen con su ensayo El sayal y la púrpura. Decía que un estado de pureza cívica y seriedad de conciencia había logrado el advenimiento de un gobierno austero y popular. Una necesidad civil de decencia frente a muchos años de explotación y fraude que postulaba como un estado de nobleza colectiva y de salud nacional (LICHTBLAU, 1985). Pues, los jóvenes de su generación eran testigos de un cambio de actitud de los argentinos con su país, que antes había sido pensado en términos de vaca holandesa por opulentos y opíparos conservadores (MALEA, 1941a; CLEMENTI, 2004). Por eso, el filósofo cordobés Adelmo Montenegro, en sus Ensayos argentinos (1984), ubica al escritor bahiense, junto a Saúl Taborda y Ezequiel Martínez Estrada, como las tres referencias intelectuales destacadas de enjuiciamiento a la crisis cultural desencadenada en la década de 1930 (MONTENEGRO; WEINBERG, 1991). Período 
que se abre, justamente, con el primer golpe de estado contra el gobierno constitucional de Yrigoyen y la apertura de una etapa dominada por el fraude político.

Así es, en la década del '30 se inició un derrotero de autocrítica sin precedentes en los intentos de comprensión y búsqueda del espíritu nacional. A los mencionados antes por Montenegro, podemos sumar los escritos del santiagueño Bernardo Canal-Feijóo que insta a un "retorno a la realidad": "es decir la tierra, la naturaleza, la pampa bárbara, frente a la Trapalanda de la civilización."6 (ARIAS SARAVIA, 2004, p. 273). Expresiones que pertenecen al santafecino Martínez Estrada, en Radiografía de la pampa de 1933, a quien se une Mallea, con sus apelaciones a luchar contra esa perversión del hombre argentino y su desapego a la tierra, descripta en Meditaciones en la costa de 1939. Aquella problemática se vincula con la Argentina invisible del hinterland provinciano y rural. Un amor pasional por su patria, representada a través de la imagen femenina (2004):

La presencia de esta tierra yo la siento como algo corpóreo. Como una mujer de increible hermosura secreta, cuyos ojos son el color, la majestad, la grave altura de sus cielos del norte, sus saltos de agua en la selva; cuyo cuerpo es largo, estrecho en la cintura, ancho en los hombros, suave. Su molicie es la provincia; su hijo vivo en el embrión: la extraña activa de los territorios, las gobernaciones, las metrópolis. Su cabeza yace cerca del trópico sin arrebatarse, a la vez próxima y distante; otra cosa. Su matriz está en el estuario, matriz fortísima de humanidad, que penetra hasta la entraña por dos potentes fluviales, su esbeltez, su sistema nervioso todo, parecen descansar, erectos, eternos, en el sistema vertebral de los Andes. Busto listo de mujer en torno a las bellas turgencias pectorales, los desiertos, las sabanas, los montes del norte indómito; el vientre: la pampa, extenso y sin ondulación como los de la normativa escultura. Sus miembros, armónicos y largos, conformados por largas colinas pétreas de la Patagonia, no sin el vello regular de los valles. Sus pies se afinan hacia el sur, descansan sobre el estrecho glacial, tocan los acantilados estériles y desiertos del Cabo de Hornos, y dejan que los ingleses - otrora despechados - se entretengan con la babucha suelta de las Malvinas. (MALLEA, 2001, p. 3).

Según Arias Saravia (2004), esa imagen mereció la atención de la poetisa chilena Gabriela Mistral por el amor físico, corporal, de Mallea hacia su lugar de origen, hacia esa carnalidad que lo conmovía y removía. Se trata de una reterritorialización, ${ }^{7}$ ciertamente existencial y paradojal que, años después, en La vida blanca de 1960, contrapuso con la metáfora del cuerpo enfermo y postrado al que invitaba a recuperarse. No obstante, permanece

Cursivas y mayúsculas del autor.

7 Arias Saravia (2004), toma este concepto de Néstor García Canclini para significar lo opuesto a la desterritorialización. Es decir, la pérdida de la relación "natural" de la cultura con los territorios geográficos y sociales. Su contracara es la reterritorialización o relocalización territorial de las viejas y nuevas producciones simbólicas para caracterizar la paradojal y dinámica opción identitaria argentina. 
esa opción por el interior, geográfico, territorial, fisonómico y, también, espiritual, invisible, que proclamaba una cierta autenticidad que distinguía del mero representar de la argentina visible. $Y$ es aquí donde se hacen evidentes los contactos con el pensador dinamarqués Sören Kierkegaard pues, esa búsqueda de lo invisible, de una interioridad que asimila lo telúrico y lo espiritual, conlleva angustia, incomprensión, dolor, pero, también, posibilidad, autenticidad, creatividad y originalidad en ese encuentro con lo que somos y nos diferencia.

\section{PERSPECTIUA KIERKERGAARDIANA}

Si bien, como sostienen Rivelli (1969) o Pintor Genaro (1976), Eduardo Mallea se nutre, durante sus años como estudiante de Derecho, de grandes autores: William Blake, Friedrich Nietzsche, Blaise Pascal, René Descartes, Immanuel Kant, David Hume, Novalis (Georg Phillipp Friedrich von Hardenberg) o Miguel de Unamuno. Incluso, del pensamiento religioso de San Agustín, San Juan de la Cruz o Santa Teresa. Y, luego de abandonar aquella carrera contra la voluntad de su padre, para dirigir el suplemento literario del diario La Nación (ROLDÁN, 2004b), mantuvo contactos intelectuales, durante sus viajes a Europa entre 1928 y 1934, con destacados escritores del viejo continente: Paul Valéry, Jean Giraudoux, Nikolái Berdiáyev, Alberto Moravia y Luigi Pirandello (LEWALD, 1977). Nos interesa, en este artículo, establecer las imbricaciones del argentino con la perspectiva kierkergaardiana (ROLDÁN, 2004b), en la construcción de sus ensayos y novelas, por los aportes que realiza desde una comunicación indirecta al campo pedagógico. Pues, la categoría de angustia que Kierkegaard (1940) ubica en el centro de la subjetividad moderna, más tarde estudiada por el psicoanalisis de Sigmund Freud y Jacques Lacan (2018), ${ }^{8}$ presente en la obra malleana en la búsqueda del país invisible, es, para el pensador nórdico, lejos de una experiencia indeseable, un aprendizaje:

La alternativa planteada es: 0 bien se aprende a angustiarse $\circ$ bien se sucumbe ante la angustia. Es caracterizada como una aventura, es decir: en ella el individuo se pone en riesgo, puede perder o ganar. Constituye, por lo tanto, una experiencia que compromete las posibilidades del hombre. (CUERVO, 2010, p. 40).

Tanto en sus ensayos en primera persona como en los personajes de sus novelas, nos encontramos con el angustioso camino de una lucha interior, un devenir existencial sobre la propia interioridad, un sufrimiento silencioso, profundo, pero que es, a su

8 "La angustia reside en la relación fundamental del sujeto con lo que hasta ahora he llamado el deseo del Otro [...] El análisis siempre ha tenido y sigue teniendo como objeto el descubrimiento de un deseo." (LACAN, 2018, p. 301). 
vez, el lugar de la escucha y el sacrificio. Es preciso tener en cuenta, de acuerdo con Dussel (1980, p. 90), que en ningún momento se exige tanto como en la pedagógica escuchar la voz del Otro, porque: "En la pedagógica la voz del Otro significa el contenido que se revela y es sólo a partir de la revelación del Otro que se cumple la acción educativa." En ese sentido, Kierkegaard es el pensador de la escucha y, por eso, la educación desde esta perspectiva consiste más en un saber escuchar que en un saber leer. Un saber oír que conlleva una oblación, o sea, un acto sagrado: sacer (sagrado) y ficare (hacer). Por lo tanto, el acto educativo consiste en transformar algo en una cosa sagrada, sacralizada, desde la voz que el otro pronuncia y anuncia en su novedad, altera la continuidad y nos puede llevar al absurdo de nuestra propia verdad (CUERVO, 2010; KIERKEGAARD, 1995). Para ejemplificar, veamos como lo que expresa Mallea en una conversación que llevan a cabo sus personajes de Fiesta en noviembre de 1944:

Todo eso, toda esa suma escandalosa de letras, żalguna vez se han acercado a usted en la forma viva de una voz? No le pregunto si los ha leido - sino si ha oído, si ha visto ${ }^{9}$ usted, al señor George Meredith, al señor Balzac, al señor Dickens, al señor Shakespeare... ¿̇Cree usted que eran grandes y triunfantes espiritus? iAh! iEran hombres tan llenos de vacilación como las peores noches de usted misma, tan inseguros, atormentados, decepcionados, fracasados en su intento, y desamparados, como las noches de usted más atormentadas, más inseguras, más oscuras, más caidas, menos convencidas de llegar al puerto de la mañanal ¿̇Qué hará usted con leerlos, con recibirlos en su triunfo, si no los recibe usted en su perdurable dolor, y en su ineficacia? (MALLEA, 1944, p. 63).

Los sujetos en las novelas del sureño transmiten aquella angustia, en ocasiones trágica, como sucede con Ágata Cruz en Todo verdor perecerá (MALLEA, 1941b), que ahondan en una subjetividad en tránsito hacia algo por venir, un deseo de liberación aprisionado en un dolor profundo, un vacío. Por eso, en las claves semánticas, que nos brindan el copenhagués y el bonaerense, podemos interpretar que educar, educare, "significa 'hacer salir' y por extensión 'poner en el mundo' en el sentido de 'sacar del vientre de la madre'." (CASTELLO; MÁRSICO, 1995, p. 33). Observamos, al respecto, que Mallea (2001) identifica la matriz con el estuario, "fortísima de humanidad", y el vientre con la pampa. Es decir, con la ondulación territorial, preñada y pregnante, de la provincia de Buenos Aires, entre el Río de la Plata y la ría de Bahía Blanca, continente de la argentinidad por nacer a partir de los dolores del parto, salir a la luz, dejar de estar en ese adentro oculto, invisible, interior, ${ }^{10}$ frente a un exterior de apariencias voluptuosas o, según Kierkegaard (1959, p. 162), de vidas estéticas contrapuestas

\footnotetext{
9 Las cursivas son del autor.

10 En Argentina, de un modo general, se acostumbra a dividir el territorio nacional entre la Capital Federal, denominados por el gentilicio de porteños, y las 23 provincias que componen el interior del país.
} 
a la vida ética: "sólo veo la belleza de la vida cuando la miro éticamente; sólo cuando miro mi propia vida éticamente veo su belleza."

Por su parte, en los entramados discursivos malleanos predomina la dialoguicidad entre los sujetos ficticios que lo representan. En cambio, en los kierkergaardianos hay una continua provocación al lector, lo interpela en cada línea, lo invita a pensar junto a él. De modo que, en ambos, se impone la mayéutica socrática, una pregunta que se deja abierta y apela a la voz de su interlocutor que le habla en la intimidad de sus profundidades subjetivas para generar "el vértigo de la libertad." (KIERKEGAARD, 1940, p. 65)." Es la posibilidad de conocerse a sí mismo en sentido helénico, según el danés, y no en aquella pretendida conciencia del yo que postulaba el idealismo moderno: "es una reflexión sobre sí mismo que es, al mismo tiempo, una acción, y por eso me he constreñido a la expresión 'elegirse a sí mismo' en vez de 'conocerse a sí mismo'." (KIERKEGAARD, 1940, p. 140-141). Habilita a un interrogante por la propia existencia, no como simple contemplación sino como una actividad fecunda que se da su propio nacimiento: "la libertad se pone a sí misma delante de sus propios ojos, en la angustia de la posibilidad, o en la nada de posibilidad, o en la nada de la angustia." (KIERKEGAARD, 1940, p. 82). Predomina, entonces, aquella pre-ocupación que se ocupa de sí mismo, que busca significados, como lo hace Ana Borel, en La ciudad junto al río inmóvil (MALLEA, [1936]): “'Qué significa esto para mí?', era la pregunta que la habitaba" (MALLEA, 1961, p. 226).

Por ende, esta angustia provocada, sacada por la pregunta de su dormitar indiferente, alterada en la negación de su nada, con-movida, es, a su vez, productiva. Es, también, un educere: "quod terra educat 'lo que la tierra produce.". (CASTELL0; MÁRSICO, 1995, p. 33). Entonces, es un movimiento de educare-educere que refiere a la producción de la tierra en la simbología malleana, a un encuentro telúrico y espiritual consigo mismo a partir de una alteridad que lo ubica ante aquella situación, lo significa, enseña (in-signare), un camino hacia su propia sensibilidad y libertad, un momento de relación con lo invisible:

\footnotetext{
"Momento" es, en alemán (Augenblick = mirada de los ojos) una expresión figurada y, por lo tanto, no es tan fácil tratar con ella. Pero en ella tenemos una hermosa palabra, digna de nuestra atención. Nada hay tan rápido como la mirada $y$, sin embargo, es conmensurable con el contenido de lo eterno.
} 
Ingeborga mirando hacia Frithjof por encima del mar es un símbolo de lo que esta palabra figurada significa. Una explosión de su sentimiento, un sollozo, una palabra, tiene ya más en sí, como sonido, la determinación del tiempo; ofrecen más presente, cuando se fija la vista en su desaparecer, y no tienen en si el presente de lo eterno en el mismo grado; así como también un sollozo, una palabra, etc., tienen la fuerza de aligerar la carga que pesa sobre el alma, porque esta carga empieza a convertirse ya en algo pasado, sólo con ser expresada. Una mirada, por el contrario, es un símbolo del tiempo; pero, bien entendido, del tiempo justamente en el conflicto fatal en que se encuentra cuando es tocado por la eternidad. (KIERKEGAARD, 1940, p. 93).

Para resumir, la educación en perspectiva kierkergaardiana es una aventura, que todos tienen que recorrer, consistente en aprender a angustiarse. Pues, quien no lo hace sucumbe $y$, por el contrario, el que lo logra habrá aprendido lo más alto que cabe aprender. El vértigo de una posibilidad, que se hunde en un abismo para luego emerger liberado del propio engaño de las apariencias del mundo visible que determinaban el destino. Es esto lo que expresan los entramados discursivos de Mallea en sus diálogos novelados, en las reflexiones de sus ensayos e, incluso, en las cavilaciones de sus personajes consigo mismo. Allí radicaba la búsqueda, obstinada, del país invisible que podemos comparar, con cierta cautela, a las críticas que Kierkegaard realizaba a la lglesia oficial del estado dinamarqués frente a un cristianismo de fondo, oculto tras el manto formal de la cristiandad instituida (CUERVO, 2010; ROLDÁN, 2004a). ${ }^{13}$

\section{A MODO DE CIERRE}

Tanto Eduardo Mallea como Sören Kierkegaard se mantuvieron al margen de la enseñanza en los ámbitos académicos. Fueron escritores de profesión. A esa actividad dedicaron toda su vida y esfuerzo. Sin embargo, el método elegido de comunicación indirecta nos permite encontrar sólidos elementos pedagógicos para analizar el sistema educativo devenido de la Europa decimonónica y su anclaje en el territorio argentino finisecular. A su vez, ambos presentan la característica de ser pensadores periféricos. Aquel, frente a la potente filosofía alemana, sobre todo a la hegemónica influencia hegeliana. Este, al reducido circulo selecto de la literatura porteña, a la cual se integró, incluso llegó a ser primero presidente y, más tarde, premio de honor de la SADE - Sociedad Argentina de Escritores - en

13 "Es sabido que Kierkegaard fue un hombre imbuido de un espíritu profundamente religioso, pero siempre manifestó serias reservas hacia las formas que la religiosidad adoptaba en su contexto social. Esto lo llevó a establecer una distinción entre 'cristianismo' - esto es, la experiencia de un vinculo personal e intransferible con el Cristo de los Evangelios - y 'cristiandad' - con ello refería a una tradición de 1900 años de lo que él llamaba la iglesia instituida.". (CUERVO, 2010, p. 10). 
1946, pero ante quien, a su vez, guardaba una prudente, y en ocasiones no tanto, distancia. Pues, contraponía la metrópoli visible al hinterland invisible afincado en sus orígenes de provincia. Asimismo, ambos fueron precursores de un pensar situado. Kierkegaard por las resonancias que tuvieron muchas de sus nociones en la filosofía existencial del siglo XX (CUERV0, 2010), y Mallea por su existencialismo en búsqueda del ser nacional que lo convierte en un agudo crítico de la herencia consanguínea, parental, con su familiaridad sarmientina, que había opuesto civilización y barbarie (ZEA, 1976).

Así es, el autor argentino realizó un agudo juicio sobre la burguesía de su tiempo desde una vertiente espiritualista que podemos llegar a identificar, en algunos aspectos, con el krausismo, aunque mucho más certeramente con una decidida perspectiva kierkergaardiana (ROLDÁN, 2004a, 2004b). La cual, se asienta en un cuestionamiento de basamento ético que se vuelca hacia la interioridad de conciencia, espiritual y es, a su vez, física, geodésica, geográfica, territorial, topográfica. Con esas piezas, Mallea, construye la trama de cuestionamientos hacia un pedagogismo de corte cientificista y normalista, acorde al clima de reacción de la época frente al positivismo (BIAGINI, 2010). ${ }^{14}$ Por ende, su discursividad pretende, en lugar de enseñar metódicamente una verdad lógica, fríamente racional, mostrar el rostro sensible de aquella Argentina invisible. Lo cual lo lleva a contraponer sus experiencias educativas con el propio descubrimiento de un otro oculto, tras el representar barbárico que, si bien no elude las antinomias sarmientinas, las rediseña, reubica y resignifica en nuevas claves de territorialización. Dado que, sostiene, tras el manto civilizatorio citadino se oculta una inherente barbarie. Y, por el contrario, en la excluida invisibilidad interior se encubre el rostro de la argentinidad naciente.

Ese otro desconocido, que pugna por renacer de sus agonías, se pone al descubierto en las palabras del escritor que "[...] recrea la realidad sensible según la profundidad en que su conciencia es capaz de abandonarla para buscarse a sí misma y ganarse por la extensión y la resonancia." (MALLEA, 1961, p. 65). Éste es el método pedagógico, indirecto, elegido. Aquello que se quiere profesar, proclamar como saber, el deseo que señala la enseñanza: "El profesor existe cada vez que la respuesta a esa pregunta está, por así decir, escrita, escrita en su aspecto o en su comportamiento [...]" (LACAN, 2018, p. 187). Re-conoce lo que debe ser enseñado, hace un recorte figurativo para evocar lo faltante, sin preocuparse de que todo encaje en una totalidad, realiza una especia de collage dice

14 "Si pasamos a la educación universitaria, cabe señalar que desde aproximadamente 1890 y hasta 1920 se fortalece la filosofía científica con el positivismo... El positivismo surge por influencias del pensamiento de Comte (1798 - 1857) y de Spencer (1820 - 1903), filósofos que dieron preeminencia a una línea biológico - psicologista tomada luego como base del aprendizaje del alumno. Desde una perspectiva, es posible considerar que el positivismo argentino inicia su presentación sostenido por la Generación del Ochenta y por los representantes del 'normalismo' en la formación de maestros." (JAFELA, 2004, p. 375). Sobre la influencia del positivismo en el campo intelectual argentino de fines del siglo XIX y principios del XX, ver también: Barboza y Fridman (2004). 
Lacan (2018). Así, libra al lector, al aprendiz, a que realice su propia interpretación, su singular interpretación, en su propia tonalidad. La perspectiva kierkergaardiana, para la educación, en las letras de Eduardo Mallea nos marcan un camino en el que: "puede haber pensamiento en la tensión que se establece entre las múltiples voces, en sus hiatos, y deja subsistir sus contradicciones como propias de la vacilación de un pensamiento que lucha consigo mismo." (CUERVO, 2010, p. 26).

En conclusión, a pesar de que el único cargo institucional que ejerció Eduardo Mallea relacionado con la educación fue en 1955, cuando fue designado embajador ante la UNESCO, nos brinda la posibilidad de comprender, a través de sus escritos, dimensiones poco exploradas del campo educativo. Para ello, hemos recurrido a la perspectiva kierkergaardiana, presente en la obra del autor, en orden a desentramar los aspectos académicos y pedagógicos hilvanados, entrelazados, en sus discursos que, de algún modo, nos permiten analizar - desde la literatura, la historia y la filosofía - los espacios geográficos e institucionales del tránsito malleano. Es decir, Bahía Blanca, ciudad del sur de la provincia de Buenos Aires, y la Capital Federal del país, en las instituciones que las componen, articulan y se asientan en voces que son reconocidas y otras que son negadas, invisibilizadas, por meros representares acomodaticios o banales enseñantes de la Argentina visible.

\section{REFERENCIAS}

ALEMIAN, C. El giro a la praxis. In: BIAGINI, H. E;; ROIG, A. A. (dir.). El Pensamiento Alternativo en la Argentina del siglo XX. Tomo I: utopía, identidad e integración (1900-1930). Buenos Aires: Biblos, 2004. p. 10-18.

ARIAS SARAVIA, L. Desterritorialización / reterritorialización, parámetros identitarios de la argentinidad. In: BIAGINI, H. E.; ROIG, A. A. (dir.). El Pensamiento Alternativo en la Argentina del siglo XX. Tomo I: utopía, identidad e integración (1900-1930). Buenos Aires: Biblos, 2004. p. 270-290.

AVEIRO, M. La universidad inconclusa. De la Ratio Sturiorum a la reforma universitaria en Mendoza (1973 - 1974). Mendoza: Ediunc, 2014.

BARBOZA, S.; FRIDMAN, S. Los congresos del centenario. In: BIAGINI, H. E.; ROIG, A. A. (dir.). El Pensamiento Alternativo en la Argentina del siglo XX. Tomo I: utopía, identidad e integración (1900-1930). Buenos Aires: Biblos, 2004. p. 427-439.

BIAGINI, H. Eduardo Mallea: una antropología crepuscular. CECIES: pensamiento latinoamericano y alternativo, 2010. Disponible en: http://www.cecies.org/articulo.asp?id=82. Acceso en: 11 oct. 2019.

BOURDIEU, P. Campo de poder, campo intelectual. Buenos Aires: Montressor, 2002.

CASTELLO, L.; MÁRSICO, C. Diccionario etimológico de términos usuales en la praxis docente. Buenos Aires: Editorial Altamira, 1995. 
CLEMENTI, H. Avances radicales: de cara al mundo y al país. In: BIAGINI, H. E.; ROIG, A. A. (dir.). El Pensamiento Alternativo en la Argentina del siglo XX. Tomo l: utopía, identidad e integración (1900-1930). Buenos Aires: Biblos, 2004. p. 185-195.

CUERVO, 0. Kierkegaard, una introducción. Buenos Aires: Editorial Quadrata, Biblioteca Nacional, 2010.

DOMÍNGUEZ, R. et al. Análisis de fuentes alternativas en la investigación filosófica. In: JORNADAS DE INVESTIGACIÓN EN HUMANIDADES: HOMENAJE A LAURA LAISECA, 4., 2011, Bahía Blanca. Anales [...] Bahía Blanca: Departamento de Humanidades, Universidad Nacional del Sur, 2011. p. 211-217.

DUSSEL, E. La pedagógica latinoamericana. Bogotá: Nueva América, 1980.

EDUARDO MALLEA reflexiona sobre sus libros, 1971. [S. l.: s. n.], 2015. Video (21 min). Publicado no canal Archivo Histórico RTA. Disponible en: https://www.youtube.com/watch?̨v=MA43140S15s. Acceso en: 11 oct. 2019.

FOUCAULT, M. La hermenéutica del sujeto. México, Fondo de Cultura Económica, 2002.

JAFELA, S. La escuela nueva en Argentina y Brasil. Un ideario pedagógico en la formación docente superior: la Universidad Nacional de La Plata. In: BIAGINI, H. E.; ROIG, A. A. (dir.). El Pensamiento Alternativo en la Argentina del siglo XX. Tomo I: utopía, identidad e integración (1900-1930). Buenos Aires: Biblos, 2004. p. 373-380.

KIERKEGAARD, S. El concepto de la angustia. Buenos Aires: Editora Espasa-Calpe, 1940.

KIERKEGAARD, S. Estética y ética en la formación de la personalidad. Buenos Aires: Editorial Nova, 1959.

KIERKEGAARD, S. Temor y temblor. México: Fontamara, 1995.

KRISTEVA, J. El Lenguaje, ese desconocido. Madrid: Editorial Fundamentos, 1988.

LACAN, J. El seminario: libro 10. La Angustia. Buenos Aires: Paidós, 2018.

LEWALD, E. Eduardo Mallea. Boston: Twayne Publishers, 1977.

LICHTBLAU, M. (ed.). Eduardo Mallea ante la crítica. Florida: Ediciones Universal, 1985.

MALLEA, E. Conocimiento y expresión de la Argentina. Obras completas. Buenos Aires: Emecé, 1961.

MALLEA, E. El sayal y la púrpura. Buenos Aires: Losada, 1941a.

MALLEA, E. Fiesta en noviembre. Buenos Aires: Losada, 1944.

MALLEA, E. Historia de una pasión argentina. Buenos Aires: Editorial Sudamericana, 2001. 
MALLEA, E. La angustia. In: MALLEA, E. La ciudad junto al río inmóvil (Novelas breves). Obras completas. Buenos Aires: Emecé, 1936.

MALLEA, E. La bahía del silencio. Buenos Aires: Editorial Sudamericana, 1940.

MALLEA, E. La vida blanca. Buenos Aires: Ediciones Sur, 1960.

MALLEA, E. Meditación en la costa. Buenos Aires: Imprenta Mercantali, 1939.

MALLEA, E. Todo verdor perecerá. Buenos Aires: Espasa-Calpe, 1941b.

MONTENEGRO, A.; WEINBERG, G. Reforma educativa: nación e ideal pedagógico. In: ACADEMIA NACIONAL DE EDUCACIÓN. Pensar y repensar la educación. Buenos Aires: Academia Nacional de Educación, 1991. p. ११३-१३९.

ROIG, A. A. Los Krausistas Argentinos. Edición corregida y aumentada. Buenos Aires: El Andariego, 2006.

ROLDÁN, A. Eduardo Mallea y su visión del nuevo hombre argentino. Antropología de Historia de una pasión argentina. [S. L.: s. n.], 2004a. Disponible en: https://www.ensayistas.org/filosofos/argentina/ mallea/roldan.htm. Acceso en: 11 oct. 2019.

ROLDÁN, A. El hombre y su obra. [S. L.: s. n., 2004b. Disponible en: https://www.ensayistas.org/filosofos/argentina/mallea/introd.htm. Acceso en: 11 oct. 2019.

ROMERO, J. L. Las ideas en la Argentina del siglo XX. Buenos Aires: Biblioteca Actual, 1987.

PINTOR GENARO, M. Eduardo Mallea, novelista. Puerto Rico: Editorial Universitaria, 1976.

POLT, J. The writing of Eduardo Mallea. Berkeley, Los Ángeles: Univesity of California, 1959.

RIVELI, C. Eduardo Mallea. La continuidad temática de su obra. New York: Las Américas Publishing Company, 1969.

SARMIENTO, D. Recuerdos de provincia. [S. L.: s. n.], 2000. Disponible en: https://www.biblioteca.org.ar/ libros/71205.pdf. Acceso en:21 jul. 2020.

ZEA, L. El pensamiento latinoamericano. Barcelona: Ariel, 1976.

Enderezo para correspondencia: Departamento de Humanidades, San Juan e 12 de Octubre, Universitario, 8000 ctx, Bahía Blanca, Argentina; lic.aveiro@gmail.com

Roteiro, Joaçaba, U. 45, p. 1-16, jan./ dez. 2020 | e23221 |E-ISSN 2177-6059 
